\title{
ANALISIS KUALITAS AIR DAN DAYA TAMPUNG BEBAN PENCEMAR DI SUNGAI CITARUM
}

\author{
Herlina Asi Suryani \\ Jurusan Teknik Lingkungan, Fakultas Arsitektur Lanskap dan Teknologi Lingkungan, \\ Universitas Trisakti, Jakarta, Indonesia
}

Email korespondensi: herlina08215027@std.trisakti.ac.id

\begin{abstract}
ABSTRAK
Sungai Citarum merupakan sungai terpanjang dan terbesar di propinsi Jawa Barat. Sungai Citarum mengalir dari hulu di Gunung wayang selatan kota Bandung dan mengalir ke utara yang bermuara di laut jawa. Dengan panjang sekitar $269 \mathrm{~km}$ mengaliri areal irigasi untuk pertanian seluas 420.000 hektar. Sungai Citarum merupakan sumber dari denyut nadi perekonomian Indonesia sebesar 20\% GDP (Gross Domestic Product) dengan berbagai industri yang berada di sepanjang sungai Citarum. Tujuan penulisan karya ilmiah ini adalah untuk mengetahui kualitas air dan daya tampung beban pencemar di Sungai Citarum. Berdasarkan Surat Keputusan Gubernur Propinsi Jawa Barat No.39 Tahun 2001, Peruntukan Sungai Citarum dan anak-anak sungainya digolongkan dalam Golongan B, yaitu peruntukan sebagai sumber air baku minum. Golongan C, yaitu peruntukan sebagai sumber air yang dapat digunakan untuk keperluan perikanan dan peternakan. Golongan D, yaitu peruntukan sebagai sumber air untuk pertanian, usaha perkotaan, industri dan pembangkit listrik tenaga air.
\end{abstract}

Kata Kunci: Kualitas Air ; Daya Tampung Beban Pencemar; Sungai Citarum

\section{PENDAHULUAN}

Sungai merupakan salah satu dari sumber daya air yang pada umumnya dapat berfungsi sebagai tangkapan air hujan, irigasi, jalur transportasi, dan sumber air minum. Air sungai merupakan salah satu komponen lingkungan yang memiliki fungsi sangat penting di dalam kehidupan manusia, termasuk untuk menunjang pembangunan ekonomi yang hingga saat ini masih merupakan tulang punggung pembangunan nasional. Fungsi lingkungan sungai yang utama salah satunya adalah untuk pengairan lahan dan untuk memenuhi kebutuhan air bersih. Seiring dengan jumlah penduduk yang semakin bertambah dan perkembangan berbagai industri yang meningkat, maka pemakaian air pun juga meningkat. Dampak dari hal tersebut adalah limbah padat (sampah) dan limbah cair (grey water dan black water) yang dihasilkan dari kegiatan manusia semakin banyak. Limbah-limbah tersebut akan mempengaruhi kualitas air sungai apabila masuk ke dalam aliran sungai. Jika kualitas air sungai menurun sampai tingkat tertentu atau melebihi batas maksimum baku mutu kualitas air maka sungai tidak dapat lagi berfungsi sesuai peruntukannya semula.

Sungai Citarum merupakan sungai terpanjang dan terbesar di propinsi Jawa Barat. Sungai Citarum mengalir dari hulu di Gunung wayang selatan kota Bandung dan mengalir ke utara yang bermuara di laut jawa. Dengan panjang sekitar $269 \mathrm{~km}$ mengaliri areal irigasi untuk pertanian seluas 420.000 hektar. Sungai Citarum merupakan sumber dari denyut nadi perekonomian Indonesia sebesar 20\% GDP (Gross Domestic Product) dengan berbagai industri yang berada di sepanjang sungai Citarum. Berdasarkan Surat Keputusan Gubernur Propinsi Jawa Barat No.39 Tahun 2001, Peruntukan Sungai Citarum dan anak-anak sungainya digolongkan dalam Golongan $\mathrm{B}$, yaitu peruntukan sebagai sumber air baku minum. Golongan $\mathrm{C}$, yaitu peruntukan sebagai sumber air yang dapat digunakan untuk keperluan perikanan dan peternakan. Golongan D, yaitu peruntukan sebagai sumber air untuk pertanian, usaha perkotaan, industri dan pembangkit listrik tenaga air.

Sungai Citarum sebagai ekosistem perairan sebenarnya memiliki kemampuan membersihkan diri (self-purification) sehingga apabila ada limbah yang masuk ke dalam sungai akan diurai secara otomatis oleh mikroorganisme dan sungai akan kembali bersih. Tetapi, hal tersebut tidak dapat terjadi dikarenakan besarnya beban pencemaran yang masuk ke sungai melebihi dari kemampuan self-purification sungai, maka yang terjadi adalah sungai tersebut 
menjadi tercemar. Tujuan penulisan karya ilmiah ini adalah untuk mempelajari kualitas air dan daya tampung beban pencemar di Sungai Citarum.

\section{TINJAUAN PUSTAKA}

\section{Gambaran Umum Sungai Citarum}

Sungai Citarum merupakan sungai terpanjang di Jawa Barat. Sungai ini membentang sepanjang 297 kilometer dari Gunung Wayang di bagian selatan Kota Bandung hingga ke utara dan berakhir di Laut Jawa yang bermuara di Muara Gembong, Kabupaten Bekasi. Sungai ini menjadi sumber air bagi sembilan kabupaten dan tiga kota di Jawa Barat, diantaranya Kabupaten Bandung, Kabupaten Karawang, Kabupaten Purwakarta, Kabupaten Cianjur, Kota Bandung, Kota Cimahi dan Kota Bekasi. Luas daerah aliran sungai Citarum mencapai 6.614 kilometer persegi. Dari sungai ini sekitar 25 juta orang di sembilan kabupaten dan tiga kota tersebut menggantungkan nasibnya. Sekitar 15 juta orang hidup di sepanjang bantaran sungai tersebut (Anonim, 2018).

Ironisnya, kondisi sungai Citarum saat ini sangat memprihatinkan. Sungai Citarum dinobatkan sebagai sungai paling tercemar di dunia. Sering terjadi banjir seakan menjadi hal yang sudah tidak asing lagi bagi warga di sekitar bantaran sungai Citarum. Ada sekitar 500 pabrik yang berdiri di beberapa daerah hulu Citarum, mayoritas diantaranya adalah pabrik tekstil. Dari seluruh pabrik yang berdiri hanya 20 persen yang mengolah limbah melalui Instalasi Pengolahan Air Limbah (IPAL), sisanya dibuang ke sub-sub DAS yang larinya ke Citarum.

\section{Daerah Aliran Sungai (DAS)}

Daerah Aliran Sungai (DAS) secara umum didefinisikan sebagai suatu hamparan wilayah/kawasan yang dibatasi oleh pembatas topografi (punggung bukit) yang menerima, mengumpulkan air hujan, sedimen dan unsur hara serta mengalirkannya melalui anak-anak sungai dan keluar pada sungai utama ke laut atau danau.

Selain itu pengelolaan DAS dapat disebutkan merupakan suatu bentuk pengembangan wilayah yang 6 menempatkan DAS sebagai suatu unit pengelolaan sumber daya alam (SDA) yang secara umum untuk mencapai tujuan peningkatan produksi pertanian dan kehutanan yang optimum dan berkelanjutan (lestari) dengan upaya menekan kerusakan seminimum mungkin agar distribusi aliran air sungai yang berasal dari DAS dapat merata sepanjang tahun. Konsep daur hidrologi sangat diperlukan terutama untuk melihat masukan berupa curah hujan yang selanjutnya didistribusikan melalui beberapa cara seperti diperlihatkan pada Gambar 1. Konsep daur hidrologi DAS menjelaskan bahwa air hujan langsung sampai ke permukaan tanah untuk kemudian terbagi menjadi air larian, evaporasi dan air infiltrasi, yang kemudian akan mengalir ke sungai sebagai debit aliran.

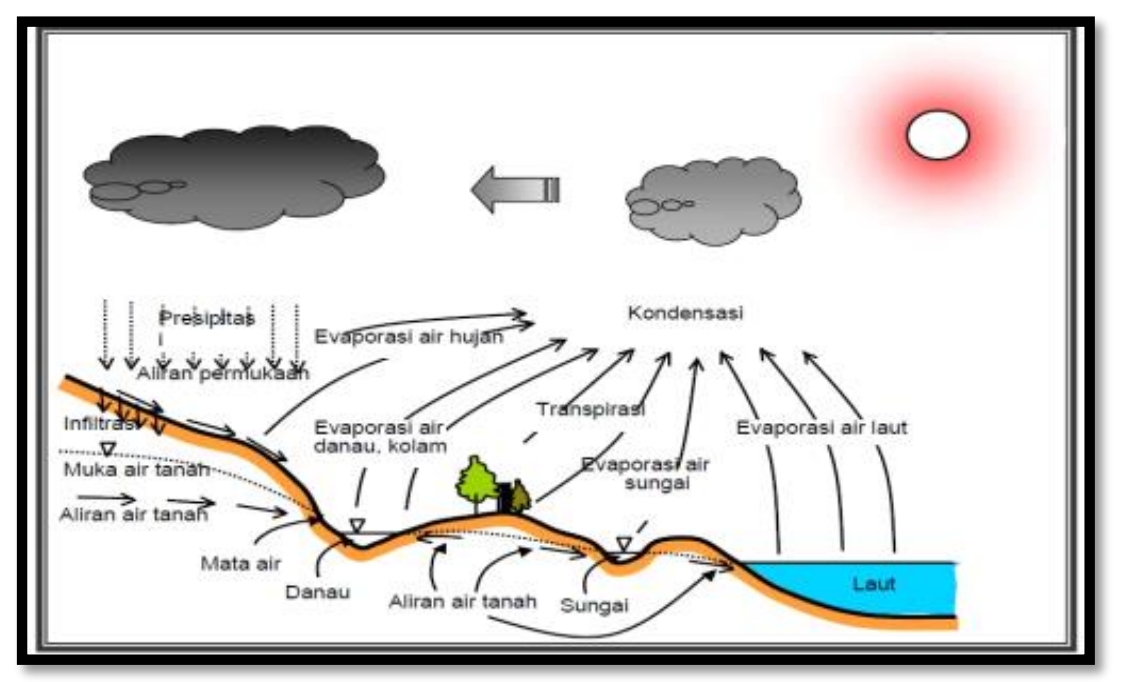

Gambar 1. Konsep daur hidrologi DAS

Dalam mempelajari ekosistem DAS, dapat diklasifikasikan menjadi daerah hulu, tengah dan hilir. DAS bagian hulu dicirikan sebagai daerah konservasi, 7 DAS bagian hilir merupakan daerah pemanfaatan. DAS bagian hulu mempunyai arti penting terutama dari segi perlindungan 
fungsi tata air, karena itu setiap terjadinya kegiatan di daerah hulu akan menimbulkan dampak di daerah hilir dalam bentuk perubahan fluktuasi debit dan transport sedimen serta material terlarut dalam sistem aliran airnya. Dengan perkataan lain ekosistem DAS, bagian hulu mempunyai fungsi perlindungan terhadap keseluruhan DAS. Dalam rangka memberikan gambaran keterkaitan secara menyeluruh dalam pengelolaan DAS, terlebih dahulu diperlukan batasan-batasan mengenai DAS berdasarkan fungsi, yaitu pertama DAS bagian hulu didasarkan pada fungsi konservasi yang dikelola untuk mempertahankan kondisi lingkungan DAS agar tidak terdegradasi, yang antara lain dapat diindikasikan dari kondisi tutupan vegetasi lahan DAS, kualitas air, kemampuan menyimpan air (debit), dan curah hujan. Kedua DAS bagian tengah didasarkan pada fungsi pemanfaatan air sungai yang dikelola untuk dapat memberikan manfaat bagi kepentingan sosial dan ekonomi, yang antara lain dapat diindikasikan dari kuantitas air, kualitas air, kemampuan menyalurkan air, dan ketinggian muka air tanah, serta terkait pada prasarana pengairan seperti pengelolaan sungai, waduk, dan danau. Ketiga DAS bagian hilir didasarkan pada fungsi pemanfaatan air sungai yang dikelola untuk dapat memberikan manfaat bagi kepentingan sosial dan ekonomi, yang diindikasikan melalui kuantitas dan kualitas air, kemampuan menyalurkan air, ketinggian curah hujan, dan terkait untuk kebutuhan pertanian, air bersih, serta pengelolaan air limbah.

\section{Kualitas Air}

Pencemaran sungai dapat terjadi karena pengaruh kualitas air limbah yang melebihi baku mutu air limbah, di samping itu juga ditentukan oleh debit air limbah yang dihasilkan. Indikator pencemaran sungai selain secara fisik dan kimia juga dapat secara biologis, seperti kehidupan plankton. Organisme plnakton yang hidup diperairan terdiri atas fitoplankton dan zooplankton.

Berdasarkan definisinya pencemaran air yang diindikasikan dengan turunnya kualitas air sampai ke tingkat tertentu yang menyebabkan air tidak dapat berfungsi sesuai dengan peruntukannya. Yang dimaksud dengan tingkat tertentu tersebut di atas adalah baku mutu air yang ditetapkan. Dan berfungsi sebagai tolok ukur untuk menentukan telah terjadinya pencemaran air. Penetapan baku mutu air selain didasarkan pada peruntukan (designated benefical water uses), juga didasarkan pada kondisi nyata kualitas air yang mungkin berada antara satu daerah dengan daerah lainnya. Oleh karena itu penetapan baku mutu air dengan pendekatan golongan peruntukan perlu disesuaikan dengan menerapkan pendekatan klasifikasi kualitas air (kelas air). Dengan ditetapkannya baku mutu air pada sumber air dan memperhatikan kondisi airnya akan dapat dihitung berapa beban pencemar yang dapat ditanggung oleh air penerima sehingga sesuai dengan baku mutu air dan tetap berfungsi sesuai dengan peruntukannya. Kualitas air pada dasarnya dapat dilakukan dengan pengujian untuk membuktikan apakah air itu layak dikonsumsi. Penetapan standar sebagai batas mutu minimal yang harus dipenuhi telah ditentukan oleh standar Internasional, standar Nasional, maupun standar perusahaan.

Di dalam peraturan Pemerintah Republik Indanesia Nomor 82 Tahun 2001 tentang kualitas dan pengendalian pencemaran air disebutkan bahwa mutu air telah diklasifikasikan menjadi 4 kelas yang dapat dilihat pada Tabel 1, dimana klasifikasiannya terdiri dari Kelas satu, air yang peruntukannya dapat digunakan untuk air baku air minum, dan untuk peruntukan lain yang mempersyaratkan mutu air yang sama dengan kegiatan tersebut. Kelas dua, air yang diperuntukannya dapat digunakan untuk prasarna/sarana rekreasi air, pembudidayaan ikan air tawar, peternakan, air untuk mengairi pertanian, dan peruntukan lain yang mempersyaratkan mutu air yang sama dengan kegunaan tersebut. Kelas tiga, yang diperuntukannya dapat digunakan untuk pembudidayaan ikan air tawar, peternakan, air untuk mengairi pertamanan, dan peruntukan lain yang persyaratan mutu air yang sama dengan kegunaan tersebut. Kelas empat, air yang diperuntukannya lain yang mempersyaratkan mutu air yang sama dengan kegunaan tersebut. 
Tabel 1. Parameter air bersih (PP No.82 tahun 2001)

\begin{tabular}{|l|l|l|l|l|}
\hline \multirow{2}{*}{$\begin{array}{c}\text { Parameter } \\
\text { Air }\end{array}$} & \multicolumn{4}{|c|}{ Kelas Air } \\
\cline { 2 - 5 } & \multicolumn{1}{|c|}{ I } & \multicolumn{1}{c|}{ II } & \multicolumn{1}{c|}{ III } & \multicolumn{1}{c|}{ IV } \\
\hline \hline $\mathrm{DO}$ & $\operatorname{Min} 6 \mathrm{Mg} / \mathrm{L}$ & $\operatorname{Min} 4 \mathrm{Mg} / \mathrm{L}$ & $\operatorname{Min} 3 \mathrm{Mg} / \mathrm{L}$ & $\operatorname{Min} 0$ \\
\hline $\mathrm{BOD}$ & $\operatorname{Max} 2 \mathrm{Mg} / \mathrm{L}$ & $\operatorname{Max} 3 \mathrm{Mg} / \mathrm{L}$ & $\operatorname{Max} 6 \mathrm{Mg} / \mathrm{L}$ & $\operatorname{Min} 12 \mathrm{Mg} / \mathrm{L}$ \\
\hline $\mathrm{COD}$ & $\operatorname{Max} 10 \mathrm{Mg} / \mathrm{L}$ & $\operatorname{Max} 25 \mathrm{Mg} / \mathrm{L}$ & $\operatorname{Max} 50 \mathrm{Mg} / \mathrm{L}$ & $\operatorname{Min} 100 \mathrm{Mg} / \mathrm{L}$ \\
\hline $\mathrm{NH}_{3}-\mathrm{N}$ & $\operatorname{Max} 0.5 \mathrm{Mg} / \mathrm{L}$ & $\operatorname{Max} 0.5 \mathrm{Mg} / \mathrm{L}$ & $\operatorname{Max} 0.5 \mathrm{Mg} / \mathrm{L}$ & $\operatorname{Max} 0.5 \mathrm{Mg} / \mathrm{L}$ \\
\hline $\mathrm{TSS}$ & $\operatorname{Max} 50 \mathrm{Mg} / \mathrm{L}$ & $\operatorname{Max} 50 \mathrm{Mg} / \mathrm{L}$ & $\operatorname{Max} 400 \mathrm{Mg} / \mathrm{L}$ & $\operatorname{Max} 400 \mathrm{Mg} / \mathrm{L}$ \\
\hline $\mathrm{pH}$ & $6-9$ & $6-9$ & $6-9$ & $6-9$ \\
\hline
\end{tabular}

Menurut Peraturan Pemerintah No. 82 Tahun 2001 beban pencemaran adalah jumlah suatu pencemar yang terkandung di dalam air atau air limbah. Beban pencemaran sungai dapat disebabkan oleh adanya aktivitas industri, pemukiman dan pertanian serta daerah komersil.

Daya tampung beban pencemaran atau beban harian maksimum total (total daily loads) merupakan kemampuan air pada suatu sumber air, untuk menerima masukan beban pencemaran tanpa mengakibatkan air tercemar.

Daya tampung beban pencemaran dapat ditentukan dengan menggunakan metode neraca massa, yaitu sebagai berikut :

$$
\mathrm{DTBP}=\mathrm{BCSBM}-\mathrm{BCT}
$$

DTBP = Daya Tampung Beban Pencemaran (kg/hari), CSBM = Beban Cemaran Sesuai Baku Mutu (kg/hari), BCT = Beban Cemaran Terukur (kg/hari)

Pencemaran air merupakan segala pengotoran atau penambahan organisme atau zat-zat lain ke dalam air, sehingga mencapai tingkat yang mengganggu penggunaan dan pemanfaatan serta kelestarian perairan tersebut (Lasy A, 2014). Masalah pencemaran air berhubungan erat dengan kualitas air. Data atau parameter kualitas air dibutuhkan dalam manajemen sungai sebagai dasar untuk penentu karakteristik air, paremeter tersebut dapat berupa parameter kimia dan fisika. Parameter Kimia meliputi Derajat Keasaman (pH), Biologycal Oxygen Demand (BOD), Chemical Oxygen Demand (COD), Nitrat, Dissolved Oxygen/ Oksigen Terlarut, dan Fosfat. Sedangkan parameter Fisika meliputi Temperatur, Kekeruhan (turbidity), Daya Hantar Listrik (DHL), dan Debit Aliran Sungai.

Tabel 2. Hasil Penelitian Terdahulu

\begin{tabular}{l|l|l}
\hline \multicolumn{1}{c|}{ Judul Paper, tahun } & \multicolumn{1}{|c}{ Penulis } & \multicolumn{1}{c}{ Hasil Penelitian } \\
\hline $\begin{array}{l}\text { Analisis Kualitas Air Dan } \\
\text { Strategi Pengendalian } \\
\text { Pencemaran Air Sungai } \\
\text { Metro di Kota Kepanjen } \\
\text { Kabupaten Malang, 2015 }\end{array}$ & $\begin{array}{l}\text { Mahyudin, Soemarno, Tri } \\
\text { Budi Prayogo }\end{array}$ & $\begin{array}{l}\text { Kondisi kualitas air sungai } \\
\text { Metro Kota Kepanjen untuk } \\
\text { konsentrasi BOD di semua } \\
\text { titik pantau dari hulu ke hilir } \\
\text { dan konsentrasi TSS di hilir } \\
\text { sungai pada titik pantau 3 } \\
\text { telah melebihi kriteria mutu } \\
\text { air kelas II yang telah } \\
\text { ditetapkan berdasarkan } \\
\text { Peraturan Daerah Provinsi } \\
\text { Jawa Timur Nomor 2 Tahun } \\
\text { 2008. }\end{array}$ \\
& & \\
\hline
\end{tabular}




\begin{tabular}{l|l|l}
\hline $\begin{array}{l}\text { Kualitas Air Sungai } \\
\text { Cisadane, Jawa Barat - } \\
\text { Banten, 2011 }\end{array}$ & $\begin{array}{l}\text { Ratna Siahaan, Andry } \\
\text { Indrawan, Dedi Soedharma, } \\
\text { dan Lilik B.Prasetyo }\end{array}$ & $\begin{array}{l}\text { Air Sungai Cisadane dari hulu } \\
\text { hingga hilir telah tercemar. } \\
\text { Kualitas air Sungai Cisadane } \\
\text { dari hulu ke hilir semakin } \\
\text { menurun. }\end{array}$ \\
\hline $\begin{array}{l}\text { Tingkat Pencemaran Air } \\
\text { Ternate Baru Kota Manado, } \\
2013\end{array}$ & $\begin{array}{l}\text { Melky Lensun, Sipriana } \\
\text { Tumembouw }\end{array}$ & $\begin{array}{l}\text { Penyebab utama pencemaran } \\
\text { air di area ini adalah limbah } \\
\text { domestik, pakan ikan dan } \\
\text { limbah industri. }\end{array}$ \\
\hline
\end{tabular}

\section{PENUTUP}

Dengan kondisi kualitas air yang ada agar dapat digunakan sebagai bahan baku maka perlu adanya intalasi pengolahan yang lebih baik pada IPA. Upaya pemerintah yang sudah direncanakan serta yang telah dikukuhkan dalam peraturan daerah semestinya segera dilaksanakan secara konsisten, seperti mempercepat pembangunan pengolahan air limbah di setiap zona. Kemudian kewajiban untuk memiliki septic tank.

\section{DAFTAR PUSTAKA}

Anonim, Laporan Akhir Pembahasanan Penetapan Keputusan Gubernur Tentang Peruntukan Sungai Citarum di Kabupaten Bandung, Purwakarta, Karawang dan Cianjur

Hasan, Mohamad. et.all. 2011. Model Pengelolaan Sumber Daya Air DAS Citarum Yang Berkelanjutan, Jurnal Sumber Daya Air. Bandung. Volume 7 No. 2, November 2011.

Indriatmoko, R.H., Wahjono, H.D., Yudo, S., dan Rahardjo, P.N., 2004. Evaluasi Lingkungan Air Tanah di DAS Citarum Hulu. Jurnal Teknik Lingkungan-P3TL-BPPT. 5. (2): 8294.

Kementerian Lingkungan Hidup. 2003. KepMen LH Nomor 110 Tahun 2003 Tentang Perhitungan Daya Tampung Beban Pencemaran Air. Jakarta: Kementerian Lingkungan Hidup.

Kementerian Lingkungan Hidup. 2003. KepMen LH Nomor 115 Tahun 2003 Tentang Pedoman Penentuan Status Mutu Air. Jakarta: Kementerian Lingkungan Hidup.

Keputusan Gubernur Jawa Barat No 39 tentang Peruntukan Air dan Baku Mutu Air pada Sungai Citarum dan Anak-anak Sungainya di Jawa Barat.

Lasy A. 2014. Application of Qual 2K Model for Predicting Water Quality in The Upper Citarum River, West Java, Indonesia. Bandung: Master Thesis ITB.

Mohajid, 2001. Rekayasa Lingkungan. Materi Kuliah Teknik Sipil dan Lingkungan-ITB.

Peraturan Pemerintah Republik Indonesia No.82 Tahun 2001 tentang Pengelolaan Kualitas Air dan Pengendalian Pencemaran Air.

Triane D. 2015. Pemodelan Kualitas Air Menggunakan Qual 2Kw. Studi Kasus: Sungai Ciliwung. Bandung: Master Thesis ITB.

Yusuf, I. 2015. Analisis Kebutuhan Air Lingkungan SDA Berdasarkan Ketersediaan Air dan Pemanfaatan Air, Jurnal Sumber Daya Air. Volume 11 No. 1 Mei 2015, Bandung: ISSN 19070276. 